centre and community support.

Outcome. I have simply divided this into short-term, longterm and the evaluation of possible modifying factors such as compliance with medication, effect of environmental change and the availability of community care.

New attacks of illness. This is to remind trainees to comment on the possibility of prevention and might include the use of depot preparations or lithium, community nursing and the education of the patient and relatives concerning the nature of the illness.

I am not unaware of the apparent naivety of the above approach, but I hope it may be helpful to those who have been glad of the Finn and German on the famous Olympus Towering Tops.

Central Hospital

ROGER W. WHITELEY

Warwick

\section{Clinical credibility of the Special Hospitals DeAR SIRS}

I am tempted to rise to the bait offered by Dr Chiswick in his challenging article (Bulletin. August 1982, 6, 130-2). I would take issue with him on factual matters and on the opinions he expresses, but shall restrict myself at present to informing members of the College that a Special Committee of the College's Council has been examining in detail the role and function of the Special Hospitals and is currently finalizing its report which will be submitted to Council in the new year.

JoHn HAMILTON

Broadmoor Hospital

Special Committee on the Special Hospitals

Crowthorne, Berks

\section{DeAr Sirs}

Dr Derek Chiswick's recent article (Bulletin, August $1982,6,130-2)$ contains several propositions which are likely to be the subject of some dispute amongst his colleagues within forensic psychiatry in general, and within the Special Hospitals in particular. Not all, for example, will be able to accept his assertions concerning the 'arbitrariness of admissions to such institutions', or that the prediction of dangerousness is not a 'legitimate medical task'.

However, it is to two of Dr Chiswick's other assertions, which seem to me to be related, that I should like to draw attention. First, he states that psychiatrists are 'medical underwriters of preventive detention'. Secondly, in recommending the establishment of a specially constituted health authority to administer the Special Hospitals, thus ending their regulation by the Department of Health, he states its first task must be the redefining of a function in a form that is clinically realistic'.

His first point is beyond dispute, but it is not only forensic psychiatrists who preventively detain. All general psychiatrists will have experience of the use of orders for the compulsory admission for observation or treatment of the mentally disordered. Indeed, the Mental Health Act (1959) specifically provides for the involuntary hospitalization of those with mental disorder who are considered to be a risk to themselves or to others. For some patients, such as those whose potentially dangerous behaviour arises in response to abnormal psychopathology (such as delusions or hallucinations), the appropriateness for compulsory detention on a short-term basis is, at least for most psychiatrists, an issue that compels little debate. The critics of contemporary psychiatry would seem to have at least some of their concerns adequately represented in the proposals of the Mental Health (Amendment) Bill, which will reduce the maximum duration of certain compulsory admissions, and increase patients' access to Mental Health Review Tribunals, even for patients detained under Section 25. (The practicability of this latter proposal is not under consideration here.)

But compulsory detention of mentally disordered individuals poses greater problems in the Special Hospitals. In terms of their source and broad diagnostic category (in Mental Health Act, 1959 terms) most new patients to, say, Broadmoor Hospital come from the courts and suffer from mental illness. By the time transfer or discharge recommendations are made for such patients they will frequently have spent longer in hospitals than had they served straight prison sentences. This is not of itself unduly surprising. For the Special Hospital psychiatrist, however, transfer or discharge of patients with mental illness will not concern so much consideration of legal or penal factors as clinical progress and some estimate of the reduction in dangerousness. While an overall improvement in mental state can be fairly readily assessed by a clinician, the difficulties of predicting subsequent behaviour, especially while the patient is in hospital, can be considerable. 'Preventive detention', then, in the absence of substantial grounds for appropriate optimism, becomes an unfortunate necessity.

The situation is less clear and even less satisfactory in the case of the 'psychopath'. The logical and nosological pitfalls of the term are all too familiar to psychiatrists (Gunn and Robertson, 1976) and others (DHSS and Home Office, 1975), and yet this designation of putative mental disorder strides through successive generations of English mental health legislation. The current Mental Health (Amendment) Bill changes little in this respect. The new idea of a.'treatability' clause is unlikely to differ in practice from the implications of the tag 'and requires or is susceptible to treatment', appended to the definition of 'psychopathic' disorder in Section 4 of the Mental Health Act, 1959. Admittedly, at various stages during the compulsory detention of such an individual indication of continued treatability will need to be 